\title{
The Announcement Effect of an Airport Expansion on Housing Prices
}

By: G. Donald Jud and Daniel T. Winkler

Jud, G. D. and D. T. Winkler. "The Announcement Effect of an Airport Expansion on Housing Prices," Journal of Real Estate Finance and Economics, vol. 33, no. 2, 2006, pp. 91-103.

Made available courtesy of Springer Verlag:

http://www.springerlink.com/content/102945/?p=71322674d99c4bc6892a932606531c7c\&pi=0

****Note: Figures may be missing from this format of the document

\begin{abstract}
:
The purpose of this study is to examine the influence of the announcement of a new airport hub on housing prices near the airport. While numerous studies of airport noise have found that high noise levels reduce property values, few have been able to measure the announcement effect on values. The results indicate that after controlling to extraneous influences, housing property prices in a 2.5 mile band from the Greensboro/High Point/Winston Salem metropolitan airport declined approximately $9.2 \%$ in the post-announcement period. In the next 1.5 -mile band, house prices declined approximately $5.7 \%$ in the post-announcement period.

Keywords Airport noise . Aircraft noise . Property values . Housing prices . Residential property

Article:

\section{Introduction}

Local economic development groups often look to improved air service as a way to quicken the pace of economic growth in their communities. This is especially true in areas where the pace of growth is perceived to be lagging. The Greensboro/High Point/Winston-Salem MSA (the Triad) is an eight-county area of central North Carolina that includes the cities of Greensboro, High Point, and Winston-Salem. The economy of the region has long been concentrated in apparel, furniture, textile, and tobacco manufacture. But by the mid-1990s, regional growth had begun to lag both state and national averages as the region's major industries faced stiffening international competition.

Local economic development groups sought a FedEx hub as a way to stimulate the region's economic growth. The new hub offered significant economic development benefits to the region. It was anticipated to initially employ 750 people, 250 full-time with an average salary of $\$ 34,000$, and a longer-term goal of employing 1,500 people. In addition, the hub would bring state tax incentives for infrastructure improvements, and also attract additional businesses related to FedEx.
\end{abstract}

In April 1998, it was announced that Federal Express had decided to locate a regional air-cargo hub at the Piedmont-Triad International Airport (PTI). The hub would require an expansion of the current airport infrastructure by adding a third runway to the current airport. Newspaper reports at the time anticipated that the hub would begin operation in May 2004, with about 20 flights a night scheduled for landing and takeoff between 10 P.M. and 4:00 A.M. The number of flights was expected to expand to 126 per night by 2009 . 
Following the initial announcement, a widely reported public debate erupted between proponents who stressed the anticipated economic benefits on area employment and income and opponents who warned of the effects on noise, pollution, and congestion. A search using the InfoTrac database revealed a total of 508 news stories and 582 opinion and editorial pieces in the Greensboro News \& Record relating to the FedEx hub between January 1998 and June $2004{ }^{1}$ This paper examines the effect of the FedEx announcement on surrounding property values. ${ }^{2}$ The first section reviews the literature on airport noise and property values. The second and third sections present the methodology and empirical model, respectively. The fourth section lays out the data and empirical results, and the final section reviews relevant findings.

\section{Literature Review}

The relationship between airport noise and property prices has been examined for a number of cities in North America and Europe. ${ }^{3}$ The results of many of the early studies have been summarized by Nelson (1980). All of the studies estimate hedonic price equations for residential property in which the level of noise is included among the attributes of the properties examined.

In order to compare the results of the studies, Nelson develops a Noise Depreciation Index (NDI), which measures the percentage decline in the price of housing for each unit increase in noise exposure. Nelson finds that the NDI averages 0.58 for the 18 airport studies he examines, that is, residential property values fall $0.58 \%$ for every decibel increase in airport noise.

More recent studies by Pennington, Topham, and Ward (1990) and Collins and Evans (1994) examine the relationship between noise and property values in Manchester, England. Pennington, Topham, Ward report no relationship between housing values and noise in Manchester during 1985-1986. Collins and Evans (1994) reexamine the Manchester data employed by Pennington, Topham, and Ward using a neural networks approach. They report that noise indeed does exert a strong, independent effect on residential values, which is negative. The effect of airport noise in the Manchester area has further been examined by Tomkins, Topham, Twomey, and Ward (1998) using 1992-1993 data. They estimate the noise discount at 0.84\% per decibel.

\footnotetext{
${ }^{1}$ For the first several months, the news stories in the News \& Record reported that six metropolitan airports were being considered for the FedEx hub. The final announcement that FedEx had chosen PTI occurred on April 13, 1998. In July 1998, the governor signed into law a multi-million dollar incentive package that included millions of dollars of tax breaks for FedEx. The first draft of the FAA environmental impact statement was released on April 6, 2000, which supported the FedEx proposal. In June 2000, the Environmental Protection Agency expressed a concern that the noise level estimates were underestimated, and state environmental regulators were concerned about damage to wetlands and wildlife habitats. During the months leading to the elections, opponents of the FedEx hub openly campaigned against politicians who supported FedEx; some politicians changed their position and some others lost the election because of their support for the hub. In November 2001, the FAA released its final impact study selecting the PTI hub as the preferred alternative of six options, and formally approved the project. However, delays in the approval process resulted in the target date for an operational hub being postponed until 2009; clearing and leveling of land began in 2004 with the expectation this phase being completed in early 2007.

${ }^{2}$ It is important to note that what we refer to as an announcement effect is actually a series of announcements that extends over multiple years (but well before the operation of the airport expansion). These announcements provide information to housing market participants who act on this information, resulting in adjustments to housing prices.

${ }^{3}$ Although our study does not directly measure the impact of a change in airport noise, noise is the primary reason cited in prior research that explains a negative impact on housing values. Therefore, we review the airport noise literature.
} 
Uyeno, Hamilton, and Briggs (1993) report a NDI of 0.68 using data for the Vancouver area in 1987. A unique feature of the Uyenro, Hamilton, and Briggs paper is the results reported for vacant land. They find the NDI is significantly higher for vacant land than for detached housing. Levesque (1994) explores the impact of noise in the area surrounding the Winnipeg airport during 1985-1986. He decomposes the effects of noise into two separate aspects: intensity and frequency. He reports that frequency is less important than loudness and the variability of the loudness during a single occurrence.

Other studies by Espey and Lopez (2000), Feitelson, Hurd, and Mudge (1996), and O'Byrne, Nelson, and Seneca (1985) explore the impact of airport noise in other metro areas, including Atlanta and the Reno-Tahoe area. While the studies employ different measures of airport noise, each reports significant noise discounts. However, Lipscomb (2003) finds that the change in noise level causes a negative but statistically insignificant change in the housing sales price for a small city located near Atlanta GA; the relatively small sample size might partially explain the insignificant noise effect.

McMillen (2004) estimates the noise discount applying to properties around Chicago's O'Hare airport. He measures noise using the annual energy mean sound level $\left(\mathrm{L}_{\mathrm{dn}}\right)$, which has become the most common measure of noise for North American airports. The $\mathrm{L}_{\mathrm{dn}}$ statistic measures average sound levels over the course of a year, including a $10 \mathrm{~dB}$ penalty for nighttime. The FAA and HUD define areas exposed to $\mathrm{L}_{\mathrm{dn}}$ levels of 65 or over as incompatible with residential housing. McMillen reports a 9.2\% discount on homes selling in severe noise areas where $\mathrm{L}_{\mathrm{dn}}$ levels are 65 or above.

Nelson (2004) conducts a meta-analysis of airport noise and property values. The study consists of 33 estimates of noise discount for 23 airports in Canada and the U.S., combining the findings of various prior studies. His results indicate that the noise discount is between 0.50 and 0.60 per decibel (dB). Properties would sell at about $10-12 \%$ less if located at $75 \mathrm{~dB}$ instead of $55 \mathrm{~dB}{ }^{4}$

Salvi (2003) applies a hedonic regression specified as a spatial error component model for single family housing data in the Zurich Switzerland airport area. He finds that airport noise decreases housing values by up to $4 \%$ for noise levels of $55 \mathrm{~dB}$ and under, and up to $27 \%$ for noise level of about $68 \mathrm{~dB}$. Although spatial autocorrelation is found to exists, its effect on the estimated coefficients and their standard errors is minimal.

\section{An Ex-ante versus Ex-post Housing Price Methodology}

Our study differs from most prior research because if focuses on the announcement effect on property values of an airport expansion to accommodate an air cargo hub. We measure the change in the property values pre- and post-announcement of the airport expansion, but before the actual construction or operational use of the new airport facility. ${ }^{5}$

\footnotetext{
${ }^{4}$ The impact of noise on property values is non-linear; the audible irritation to humans from noise, as measured per decibel $(\mathrm{dB})$,) is greater per $\mathrm{dB}$ increase at higher levels of noise than per $\mathrm{dB}$ increase at lower levels of noise. Theebe (2004) analyzed 160,000 transactions in the Western part of The Netherlands, and found very little impact of noise below $65 \mathrm{~dB}$ from trains, vehicular traffic, and airplanes on property values. However, the estimates were relatively large between 66 and $75 \mathrm{~dB}$, especially for more expensive properties.

${ }^{5}$ During the period of study, the airport expansion was announced and studies of the environmental impact were conducted during the approval process. However, the actual airport expansion had not begun.
} 
A potential problem with almost all airport noise studies is that they examine the effects of noise in an ex post dimension, that is, after the noise level has increased and property markets have had time to adjust. The problem with this approach is that after the fact, noise is very highly correlated with other aspects of the property market: air pollution, traffic congestion, and other neighborhood/location amenities. This is the point made by Pennington, Topham, and Ward in explanation of their insignificant findings for the Manchester area. They suggest that noise is inextricably bound up with other, more important neighborhood/location variables so that its effect cannot be reliably untangled using property data collected after the noise level has changed.

To overcome this problem, we propose an event study methodology. ${ }^{6}$ Using this approach, we are able ex ante to study effects of the noise announcement. Because the announcement of a change in noise (both frequency and intensity) does not change the actual noise level, we are unable to directly examine the effect of a change in noise. Instead, we assume that the expectation of future noise brought about by the announcement is related to distance from the airport. ${ }^{7}$ Thus, the announcement of a significant change in airport traffic (and noise) will affect the shape of value-distance gradient for properties surrounding the airport. ${ }^{8}$

\section{Empirical Model}

To examine the effect of the FedEx announcement on the value of surrounding residential property, we posit the following hedonic price model for property $i$ at time $t$ :

$$
\ln P_{i, t}=a_{0}+a_{1} T_{i, t}+a_{2} D_{i, t}+a_{3} A_{i, t}+a_{4} C_{i, t}+u_{i, t}
$$

\footnotetext{
${ }^{6}$ The concept of event study methodology was coined in the finance literature as a method used to study the impact of new information (usually from an announcement) on stock prices. The methodology developed by Fama, Fisher, Jensen, and Roll (1969) used the market model in a pre-announcement period to estimate the regression parameters. In the subsequent announcement period, these parameters were used to provide regression residuals. A cumulative change in residuals indicated a significant announcement effect. Work by Brown and Warner $(1980,1985)$ tested variations of event study methodology. Karafiath (1988) demonstrates that the use of dummy variables for the days of the announcement period provides identical results to the use of the regression residuals. Burnett, Carroll, and Thistle (1995) offer a general methodology to correct for changes in market parameters.

${ }^{7}$ The final Record of Decision by the FAA was issued on 12-31-01. The noise impact estimates were provided in the report. A total of 178 people and 75 homes would be within the DNL 65 dBA noise contour without the expansion. With the expansion, 698 people and 262 homes would be within the contour. Of these, 126 people and 53 homes would be inside the 70dBA contour. Also, 549 people and 231 homes (of the 628 people and 262 homes) would experience an increase of DNL 1.5 dBA within the DNL 65 dBA ("Threshold of Significance" for noise impacts). This information does not necessarily coincide with the distance bands used in this study, so it is not possible to meaningfully equate the $\mathrm{dBA}$ information to the findings our study. In addition, there have been revisions to the dBA impact and the contours since the report was issued.

${ }^{8}$ Because it does not use a measure of noise level, but instead, includes structural variables measuring distance bands (pre- and post-event) from the airport, this study measures the anticipated "net'" effect of the airport expansion. Although the principal concern of most communities that are considering an airport expansion is increased noise, other negative effects would include expected construction and traffic congestion, while anticipated longer-term advantages include more employment and shopping, as well as enhancement of roads and other infrastructure. Nonetheless, the literature on airport expansion points generally points to noise as the primary negative effect.
} 
where

$\ln P_{i, t} \quad \log$ of the real sales price (sales price adjusted by the consumer

price index CPI-U),

$T_{i, t} \quad$ time of sale,

$D_{i, t} \quad$ a vector of distance bands,

$A_{i, t} \quad$ a vector of housing property characteristics,

$C_{i, t} \quad$ vector of city location variables,

$u_{i, t} \quad$ a stochastic error term.

The coefficients of the variables are denoted by $\mathrm{a}_{0}, \mathrm{a}_{1}, \ldots \mathrm{a}_{4}$. The distance variables include distance bands (in miles) from the airport (d) for $0<\mathrm{d} \leq 2.5$ and $2.5<\mathrm{d} \leq 4.0$. The distance bands capture the additional impact on property values of proximity to the airport.

The effect of the announcement on values is revealed by estimating Eq. 1 using data in the period prior to the FedEx announcement (1997-1998) and again with data following the announcement (1999:1-2004:2). ${ }^{9}$ The effect of the announcement on property values is revealed by comparing the estimated coefficients on the distance variable. If $\alpha_{1}$ is the coefficient on the distance variable estimated in the pre-announcement period and $\gamma_{1}$ is the coefficient estimated for the postannouncement period, the effect of the FedEx announcement is $\left(\gamma_{1}-\alpha_{1}\right)$. The test statistic for statistical significance is a Wald statistic for structural change with unequal sub- sample variances:

$$
t=\left[\left(\gamma_{1}-\alpha_{1}\right)^{2} /\left(s_{\lambda}^{2}+s_{\alpha}^{2}\right)\right]^{0.5}
$$

where $s_{\lambda}$ and $s_{\alpha}$ are the standard errors of $\gamma_{1}$ and $\alpha_{1}$, respectively [Greene (1990), p. 189]. ${ }^{10}$

\section{Sample Data and Empirical Results}

The Piedmont-Triad International Airport is located adjacent to I-40 about midway between the town limits of Greensboro and Kernersville, NC. Our sample is drawn from properties sold in Guilford and Forsyth Counties from January 1997 through June 2004 (see Fig. 1). The Forsyth County portion of the sample includes only the eastern portion of the county defined by zip code 27284, which subsumes the town of Kernersville. The sample includes 29,614 properties. Of the total sample, 8,957 were sold during 1997-1998, while 20,657 were sold from 1999:1-2004:2.

\footnotetext{
${ }^{9}$ Although the announcement that FedEx chose the PTI Airport for its hub occurred in April 1998, we decided to separate the sample into the 1997:1-98:4 and 1999:1-2004:2 time frames for four reasons. First, several months of vociferous debates occurred, and there was sentiment suggesting that FedEx could have reversed its decision. It was clear that the FedEx hub had organized opposition who would be challenging a FedEx hub in court. Second, the sample used in this study consists of closing prices which can occur up to several months after making an offer on a property. Such new homebuyers could have made offers before the final announcement, or at least, without the knowledge of subsequent information. Third, while it would be possible to exclude altogether a portion of the latter observations occurring in the pre-event sample; a large sample is needed, and we wanted to minimize the influence of changes to area that were unrelated to FedEx hub announcement (which might occur by extending the pre-event sample using observations prior to 1997). Fourth, the inclusion of data in the "pre-event" period would work in favor of the null hypothesis that the FedEx announcement had no effect because some of the negative impact would be captured in the pre-event dummy distance band coefficients, making the difference in the pre- and post-event distance bands smaller.

${ }^{10}$ Although a dummy variable pre- and post-event could be introduced into Eq. 1, this specification would assume that the other coefficients would not change pre- and post-event. We find that this assumption is not true. Also, the use of Eq. 2 allows for variances of the pre- and post-sample to be statistically different.
} 
Table 1 shows the means and standard deviations for all variables in the sample. The sample sizes are 8,957 and 20,657 for the pre-announcement and post-announce-

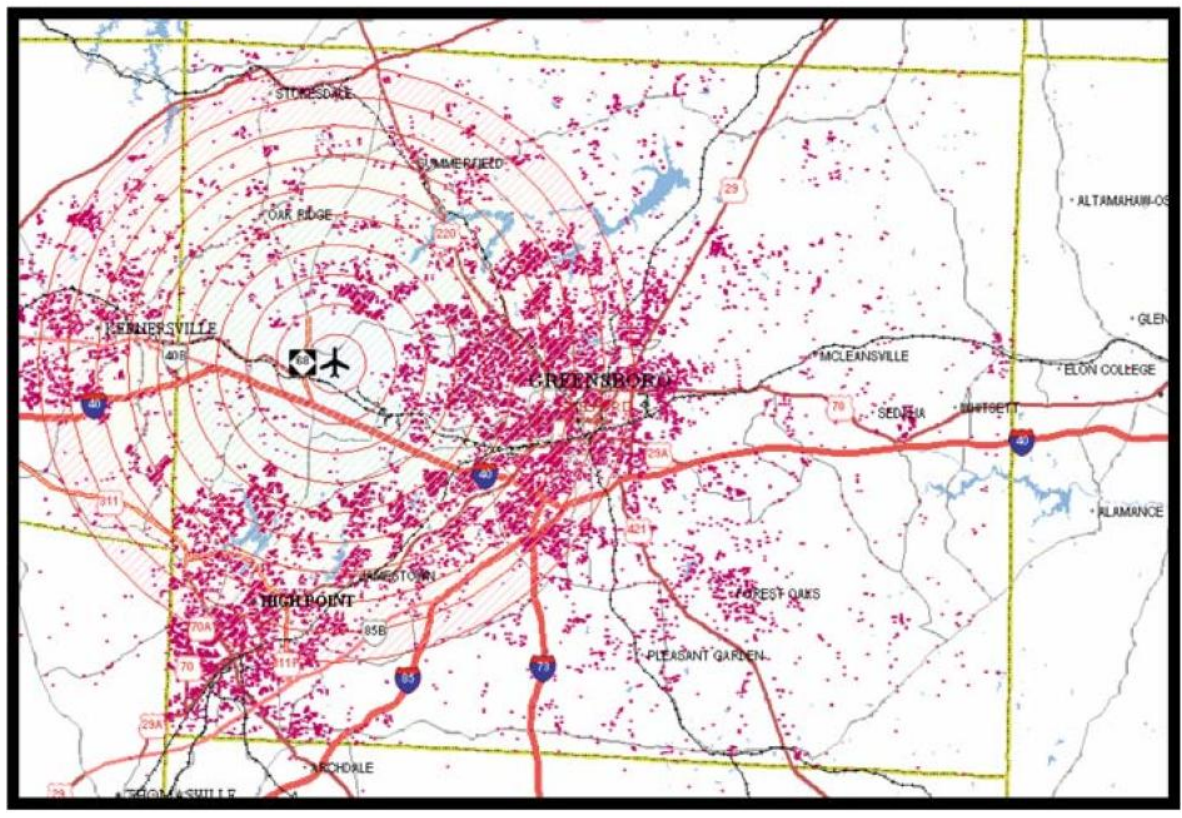

Fig. 1 Sales of single-family homes surrounding the Piedmont-Triad Airport, 1997.01-2004.06. The circular lines are placed one mile apart

Table 1 Means and standard deviations

\begin{tabular}{|c|c|c|c|c|c|c|}
\hline \multirow[t]{2}{*}{ Variable } & \multicolumn{2}{|c|}{ Pre-announcement } & \multicolumn{2}{|c|}{ Post-announcement } & \multicolumn{2}{|c|}{ Total sample } \\
\hline & Mean & Std. Dev. & Mean & Std. Dev. & Mean & Std. Dev. \\
\hline Event & - & - & - & - & 0.6975 & 0.45933 \\
\hline Time & 1.9983 & 0.5698 & 5.4949 & 1.5796 & 4.4373 & 2.1020 \\
\hline LE 2.5 miles & 0.0255 & 0.1575 & 0.0292 & 0.1684 & 0.0281 & 0.1651 \\
\hline GT 2.5 \& LE 4.0 miles & 0.0568 & 0.2315 & 0.0555 & 0.2289 & 0.0559 & 0.2297 \\
\hline Ave. house value & 124,266 & 29,592 & 125,279 & 28,870 & 124,972 & 29,094 \\
\hline Large lot & 0.1384 & 0.3454 & 0.1927 & 0.3944 & 0.1763 & 0.3811 \\
\hline Fireplace & 0.9221 & 0.5785 & 0.9427 & 0.5519 & 0.9365 & 0.5602 \\
\hline Bedrooms & 3.3132 & 0.6976 & 3.3576 & 0.6862 & 3.3441 & 0.6899 \\
\hline Full baths & 2.1345 & 0.9384 & 2.0157 & 0.7233 & 2.0517 & 0.7964 \\
\hline Half baths & 0.5077 & 0.6413 & 0.5554 & 0.5462 & 0.5409 & 0.5770 \\
\hline Garage & 1.2127 & 0.9407 & 1.304 & 0.9713 & 1.2764 & 0.9631 \\
\hline Stories & 0.7951 & 1.0382 & 1.0305 & 1.0461 & 0.9593 & 1.0493 \\
\hline Age & 20.3055 & 20.8458 & 20.0939 & 21.0518 & 20.1579 & 20.9896 \\
\hline New & 0.1159 & 0.3201 & 0.0939 & 0.2917 & 0.1006 & 0.3008 \\
\hline Greensboro & 0.5723 & 0.4948 & 0.5494 & 0.4976 & 0.5563 & 0.4968 \\
\hline High point & 0.188 & 0.3907 & 0.1871 & 0.39 & 0.1873 & 0.3902 \\
\hline Kernersville & 0.1074 & 0.3096 & 0.1269 & 0.3329 & 0.1210 & 0.3262 \\
\hline Log of sales price & 11.2906 & 0.5889 & 11.359 & 0.5724 & 11.3383 & 0.5783 \\
\hline$n$ & 8,957 & & 20,657 & & 29,614 & \\
\hline
\end{tabular}


ment periods. ${ }^{11}$ Approximately $2.8 \%$ of the sample is within a 2.5 -mile distance band of the airport, and 5.6\% within the next 1.5 miles of the airport. For the pre- announcement sample, 228 properties are within 2.5 miles of the airport and 509 within the next 1.5 mile band. For the postannouncement sample, the numbers are 603 and 1,146 properties, respectively.

A least-squares estimation of Eq. 1 is shown in the Appendix. This model has adjusted R-squares of 0.62 for the pre-announcement period and 0.71 for the post- announcement period; the Fvalues are highly statistically significant. These results, however, have econometric problems including heteroscedasticity and spatial correlation.

Inferences based on least squares are biased in the presence of heteroscedasticity (Greene, 1990). White's (1980) general test indicates that the least squares estimator is not consistent, and therefore, heteroscedasticity is a problem. ${ }^{12}$ An examination of the residuals indicates that the heteroscedastic disturbance is directly related to time of sale (Time). When error variances vary directly with an independent variable, Pindyck and Rubinfeld (1981) suggest a data transformation using weighted least squares. ${ }^{13}$

Spatial autocorrelation is a frequent problem associated with housing price data. Accordingly, it is important to identify the presence of spatial correlation and correct for it if necessary. ${ }^{14}$ The simultaneous autoregressive (SAR) model is commonly used to correct for spatial correlation in hedonic pricing models. ${ }^{15}$ In the SAR model, house prices are assumed to be dependent on surrounding house prices. In addition, however, the independent variables (property characteristics) are assumed to be correlated with housing characteristics of surrounding houses (Griffith, 1993).

\footnotetext{
${ }^{11}$ Testing for the difference in the pre- and post-event means, assuming they have unequal variances, all variables are statistically different at the 0.05 level except the means for the distance bands, age of the house, and dummy variable houses located in the city of High Point. This finding is not surprising given the very large sample size. ${ }^{12}$ The White statistic is 458.38 for the pre-announcement sample and 1,049.81 for the post-announcement sample. These statistics are $\mathrm{x}^{2}$ distributed, and are significant at the 0.0001 level.

${ }^{13}$ The weighted least squares procedure is based on the Time variable. Using this procedure, the original intercept becomes a variable term and the slope parameter associated with the of the Time variable becomes the new intercept term. For more details, see pp 145-146 of Pindyck and Rubinfeld (1981).

${ }^{14}$ Spatial autocorrelation occurs when similar values cluster in a geographical area. Similar to time series autocorrelation, positive spatial autocorrelation can be measured on a continuum from 0 to 1 , with the latter associated with perfect positive spatial autocorrelation. A large positive spatial autocorrelation means that neighboring properties have similar values that are not independent of each other. The coefficients and standard errors are affected by spatial autocorrelation, and therefore, corrections are necessary to correct for it.

${ }^{15}$ The SAR model is appropriate in situations involving higher order spatial dependency (a stronger effect), whereas the conditional autoregressive model (CAR) assumes only a first-order dependency (Griffith, 1993). When compared to the simpler autoregressive response (AR) model, the SAR model does not assume the error terms to be independent of the dependent variable, leading to a complicated error term covariance matrix.
} 
Table 2 Pre- and post-announcement spatial autoregressive model results

\begin{tabular}{|c|c|c|c|c|}
\hline \multirow[t]{2}{*}{ Variable } & \multicolumn{2}{|c|}{ Pre-announcement } & \multicolumn{2}{|c|}{ Post-announcement } \\
\hline & Coefficient & $t$-value & Coefficient & $t$-value \\
\hline Intercept & 10.2762 & 149.95 & 10.4763 & 260.43 \\
\hline Time & 0.0118 & 1.44 & -0.0084 & -5.81 \\
\hline LE 2.5 miles & -0.0024 & -0.07 & -0.0992 & -5.84 \\
\hline GT $2.5 \&$ LE 4.0 miles & -0.0272 & -1.05 & -0.0875 & -6.78 \\
\hline Large lot & 0.0392 & 4.89 & 0.0143 & 12.83 \\
\hline Fireplace & 0.1860 & 23.00 & 0.1447 & 37.47 \\
\hline Bedrooms & 0.1960 & 25.99 & 0.1281 & 36.60 \\
\hline Full baths & 0.0524 & 11.58 & 0.1404 & 42.90 \\
\hline Half baths & 0.0369 & 5.41 & 0.0862 & 21.59 \\
\hline Garage & 0.1389 & 24.71 & 0.1136 & 45.79 \\
\hline Stories & 0.0318 & 6.25 & 0.0366 & 15.43 \\
\hline Age & -0.0047 & -16.53 & -0.0047 & -35.04 \\
\hline New & 0.0239 & 1.54 & 0.0346 & 5.43 \\
\hline Greensboro & -0.0356 & -1.86 & -0.0031 & -0.37 \\
\hline High point & -0.2108 & -9.50 & -0.1995 & -19.68 \\
\hline Kernersville & -0.1377 & -5.70 & -0.1670 & -15.26 \\
\hline$n$ & 8,957 & & & 20,657 \\
\hline SAR spatial parameter & 0.4640 & 30.35 & 0.6530 & 75.32 \\
\hline
\end{tabular}

The empirical findings for the SAR model using the transformed heterscedasticity-consistent variables are reported in Table $2 .{ }^{16}$ The SAR estimates are based upon five nearest neighbors and a geometrically declining weight of 0.85 for the next nearest neighbor. ${ }^{17}$ The findings suggest that spatial autocorrelation is relatively large and statistically significant in the pre- and postevent samples, increasing from 0.46 in the pre-announcement sample to 0.65 post announcement.

As shown in Table 2, the coefficients of the independent variables have the anticipated signs and magnitudes. The Time trend variable shows that the real value of houses increased $1.2 \%$ per year in the pre-announcement time period and decreased $0.84 \%$ per year in the post-announcement period. The negative price trend in the post-announcement period reflects the effects of the 2001 recession and the severe loss of textile, apparel, and furniture jobs on the economy of the Greensboro NC MSA.

In the pre-event time period, properties located near the airport (within 4.0 miles) sold for slightly lower prices, on average, than other more-distant properties. The coefficients of -0.24 and $-2.72 \%$, however, are not statistically significant. Properties within the city limits of High Point and Kernersville had lower prices compared to those outside the city limits of the towns.

Table 3 Test of pre- and post announcement distance variables.

\begin{tabular}{lll}
\hline Distance variable & SAR coefficient difference & SAR Wald $t$-test \\
\hline LE 2.5 miles & -0.0968 & 2.4445 \\
GT 2.5 \& LE 4.0 miles & -0.0603 & 2.0764 \\
\hline
\end{tabular}

\footnotetext{
${ }^{16}$ The SAR model was estimated using Statistics Toolbox 2.0 software (written by Kelley Pace and Ronald Barry) and Matlab 6.5.

${ }^{17}$ SAR models were tested with many variations including changes to the number of nearest neighbors as well as different geometrically declining weights. The findings are robust to the particular specification used. In addition, a Delaunay triangle spatial weight matrix was tested; the results reported here for five nearest neighbors indicate a slightly higher spatial correlation than using the Delaunay triangle spatial weight matrix.
} 
While many of the amenity coefficients changed somewhat in the pre- and post- event equations, the number of bedrooms and bathrooms were the most notable. Bedrooms became significantly less important, while the number of full- and half- bathrooms became much more important, measured by the impact on selling price. As expected, the effect age on house price was negative. The age coefficients suggest that property values fall $0.5 \%$ per year.

Of particular interest in this study are the magnitudes of the coefficients on the distance bands in the pre- to the post-announcement periods. ${ }^{18}$ Prior to the announcement, properties within 2.5 miles were subject to a $0.2 \%$ discount. ${ }^{19}$ Following the announcement, these properties sold at a $9.4 \%$ discount, an increase of $9.2 \%$. Properties that were more than 2.5 miles from the airport but no more than 4.0 miles from the airport had a $2.7 \%$ discount before the event and an $8.4 \%$ after the event; this difference is $5.7 \%$.

The Wald t-tests in Table 3 provide a formal test for comparing the distance coefficients before and after the announcement period. The results of the Wald tests provide evidence that the FedEx announcement was associated with a significant negative impact on properties located within 2.5 miles of the airport. The difference in the regression coefficients denoting properties less than or equal to 2.5 miles from the airport is -0.0968 , and this difference has a $t$-value of 2.45 which is statistically significant at the 0.01 level. The distance coefficient for $2.5<\mathrm{d} \leq 4.0$ indicates a difference of -0.0603 with a t-value of 2.08 ; this difference is statistically significant at the 0.05 level. These findings suggest a strong localized effect on housing values for properties located close to the airport.

\section{Conclusion}

This study examines the announcement effect on housing values of building an air- cargo hub in the Greensboro/High Point/Winston-Salem metropolitan area. The study differs from other studies of airport noise by focusing on the change in pre- versus post-announcement housing prices, prior to the actual construction and operation of the proposed airport hub. The methodology employed in this study is useful for city planners, real estate professionals and others who desire to measure the net effect on housing values of an airport expansion prior to actual construction.

It has the advantage of measuring the change in housing prices ex ante instead of ex post. This is important because neighborhood and locational attributes often change substantially after an airport expansion is operational. Although noise level measurement is possible ex post, the net effect is very difficult to determine years later.

The results of the study indicate that even after controlling for housing, neighborhood, and locational characteristics, there is a $9.2 \%$ decrease in housing prices for properties located within 2.5 miles from the Greensboro Airport. A 5.7\% decrease occurs for properties in the next 1.5-

\footnotetext{
${ }^{18}$ In addition to these distance bands, other bands were tested. The next 1.5 mile distance band (where $4.0<\mathrm{d}<$ 5.5), for example, have relatively small but positive pre-and post-announcement coefficients, but the difference in the two coefficients was not statistically significant. Therefore, price declines beyond the 4-mile radius are relatively small and not statistically significant.

${ }^{19}$ The percentage impacts of a one-unit change in the distance dummy variables on sales price are given by $\mathrm{e}^{\mathrm{x}}-1$, where $\mathrm{x}$ is the estimated coefficient on the particular dummy variable.
} 
mile band surrounding the airport. With an average house price of $\$ 154,182$ in the 2.5 mile band during the post- announcement period and a 9.2\% discount, the average loss per house seller is $\$ 15,622$ or about $\$ 9.42$ million for the post-event sample. In the next 1.5 -mile band (between 2.5 and 4 miles), the average house sold for $\$ 151,070$, and an average loss of $\$ 9,131$ per house seller was incurred or about $\$ 10.46$ million in total during the post-event sample.

Although the event methodology used in this study differs from the NDI approach employed by Nelson (1980) and others, the discounts from the pre- announcement to the post-announcement period provide information about the estimated change in the level of noise. Nelson's (2004) finding of a 10-12\% discount for properties located at $75 \mathrm{~dB}$ instead of $55 \mathrm{~dB}$ suggests that residents in the 2.5 mile radius at PTI International Airport are expecting an increase in noise levels of perhaps $15 \mathrm{~dB}$ or more. Using NDI measures from various studies ranging from 0.50 to $0.84 \%$ per decibel, a $9.2 \%$ decrease in housing prices suggests an increase in the noise level of 11 to $18 \mathrm{~dB}$. For the next 1.5 -mile band, the $5.7 \%$ decrease indicates a noise level increase of 7 to $11 \mathrm{~dB} .^{20}$

As with any event study methodology, even after resolving measurement problems, the announcement impact of the event is likely to differ from the actual. Therefore, one should not necessarily assume that the estimated discount for properties in the 2.5-mile band around the airport will continue to prevail once the air-cargo hub is operational. Changes to the infrastructure and unanticipated employment clusters, for example, together with lower or higher than expected noise levels and flight frequencies might propel properties prices in the 2.5-mile zone to sell at larger or smaller discounts than estimated here. Additional study of the actual impact of the air-cargo hub following construction and operation would be necessary to measure this change.

However, in the short-run, the findings of this study indicate that homeowners nearest an airport may have reason to be concerned that the announcement of an airport expansion will have a noticeable negative effect on housing prices. While the magnitude of the housing price decrease might change depending on the particular airport expansion plans and community in question, there is evidence that an announcement can have a detrimental impact on housing prices for properties nearest an airport, as property markets anticipate negative consequences to follow.

\section{Appendix}

\footnotetext{
${ }^{20}$ Caution should be exercised when converting the distance band housing price changes to anticipated changes in the noise level because (1) the NDI measures are estimated using data from other airports with unique environmental characteristics, (2) the effect of a given increase in NDI changes depending on the initial level of noise, and (3) the band represents a radius around the airport which might not be uniform because of the projected landing patterns.
} 
Pre- and Post-Announcement OLS Regression Model Results

\begin{tabular}{|c|c|c|c|c|}
\hline \multirow[t]{2}{*}{ Variable } & \multicolumn{2}{|c|}{ Pre-Announcement } & \multicolumn{2}{|c|}{ Post-Announcement } \\
\hline & Coefficient & $t$-value & Coefficient & $t$-value \\
\hline Intercept & 9.9502 & 343.99 & 10.0619 & 649.53 \\
\hline Time & 0.0229 & 3.37 & -0.0105 & -7.58 \\
\hline LE 2.5 miles & -0.0108 & -0.43 & -0.1085 & -8.36 \\
\hline GT $2.5 \&$ LE 4.0 miles & -0.0532 & -3.10 & -0.0618 & -6.42 \\
\hline Large lot & 0.0862 & 6.94 & 0.0866 & 14.38 \\
\hline Fireplace & 0.2351 & 31.12 & 0.2006 & 44.31 \\
\hline Bedrooms & 0.2318 & 32.73 & 0.1461 & 34.68 \\
\hline Full baths & 0.0708 & 15.23 & 0.2304 & 56.68 \\
\hline Half baths & 0.0429 & 6.19 & 0.1300 & 25.27 \\
\hline Garage & 0.1570 & 29.96 & 0.1413 & 49.42 \\
\hline Stories & 0.0518 & 10.60 & 0.0325 & 11.13 \\
\hline Age & -0.0033 & -14.04 & -0.0028 & -21.59 \\
\hline New & 0.0450 & 3.42 & 0.0580 & 7.45 \\
\hline Greensboro & 0.0061 & 0.46 & 0.0203 & 2.84 \\
\hline High point & -0.1736 & -11.37 & -0.1678 & -20.44 \\
\hline Kernersville & -0.1239 & -7.56 & -0.1500 & -17.78 \\
\hline$n$ & 8,957 & & & 20,657 \\
\hline Adjusted $R^{2}$ & 0.6165 & & & 0.7092 \\
\hline$F$-Value (Model) & 960.91 & & & 3358.69 \\
\hline
\end{tabular}

\section{References}

Brown, S.J., \& Warner, J.B. (1980, September). Measuring security performance. Journal of Financial Economics, 8(3), 205-258.

Brown, S.J., \& Warner, J.B. (1985, March). Using daily stock returns: The case of event studies. Journal of Finance Economics, 14(1), 3-31.

Burnett, J.E., Carroll, C., \& Thistle, P. (1995, Winter). Implications of multiple structural changes in event studies. The Quarterly Review of Economics and Finance, 35(4), 467-481.

Collins, A., Evans, A. (1994, May). Aircraft noise and residential property values. Journal of Transport Economics and Policy, 28(2), 175-197.

Espey, M., Lopez, H. (2000, Summer). The impact of airport noise and proximity on residential property values. Growth Change, 31(3), 408-419.

Fama, E.F., Fisher, L., Jensen, M.C., Roll, R. (1969, February). The adjustment of stock prices to new information. International Economic Review, 10(1), 1-21.

Feitelson, E.I., Hurd, R.E., Mudge, R.R. (1996, September). The impact of an airport noise on willingness to pay for residences. Transportation Research. Part D, Transport and Environment, 1(1), 1-14.

Greene, W.H. (1990). Econometric analysis. New York: MacMillan.

Griffith, D.A. (1993). Spatial regression analysis on the PC: Spatial statistics using SAS.

Washington, District of Columbia: Association of American Geographers.

Karafiath, I. (1988, August). Using dummy variables in event methodology. Financial Review, 23(3), 351-357.

Levesque, T.J. (1994, May). Modelling the effects of airport noise on residential housing markets. Journal of Transport Economics and Policy, 28(2). 199-210. 
Lipscomb, C. (2003, November). Small cities matter too: The impacts of an airport and local infrastructure on housing prices in a small urban city. Review of Urban and Regional Development Studies, 15(3), 255-273.

McMillen, D.P. (2004, May). Airport expansions and property values: The case of Chicago O' Hare airport. Journal of Urban Economics, 55(3), 627-640.

Nelson, J.P. (1980, January). Airports and property values. Journal of Transport Economics and Policy, 14(1), 37-52.

Nelson, J.P. (2004, January). Meta-analysis of airport noise and hedonic property values: Problems and prospects. Journal of Transport Economics and Policy, 38(1), 1-28.

O’Byrne, P.H., Nelson, J.P., \& Seneca, J.J. (1985, June). Housing values, census estimates, disequilibrium, and the environmental cost of airport noise: A case study of Atlanta. Journal of Environmental Economics and Management, 12(2), 169-178.

Pennington, G., Topham, N., \& Ward, R. (1990, January). Aircraft noise and residential property values adjacent to Manchester International Airport. Journal of Transport Economics and Policy, 24(1), 49- 59.

Pindyck, R.S., \& Rubinfeld, D.L. (1981). Econometric models and economic forecasts. New York: McGraw-Hill.

Salvi, M. (2003, April). Spatial estimation of the impact of airport noise on residential housing prices. Working Paper, Zu"rcher Kantonalbank.

Theebe, M.A.J. (2004, March-May). Planes, trains, and automobiles: The impact of traffic noise on house prices. Journal of Real Estate Finance and Economics, 28(2-3), 209-234.

Tomkins, J., Topham, N., Twomey, J., \& Ward, R. (1998, February). Noise versus access: The impact of an airport in an urban property market. Urban Studies, 35(2), 243-258.

Uyeno, D., Hamilton, S.W., Briggs, A.J.G. (1993, January). Density of residential land use and the impact of airport noise. Journal of Transport Economics and Policy, 27(1), 3-18.

White, H. (1980, May). A heteroscedasticity-consistent covariance matrix estimator and a direct test for heteroscedasticity. Econometrica, 48(4), 817-838. 